\title{
BMI and Lower Extremity Injury in U.S. Army Soldiers, 2001-2011
}

\author{
Adela Hruby, PhD, MPH, ${ }^{1,2}$ Lakmini Bulathsinhala, MPH, ${ }^{3,4}$ Craig J. McKinnon, MPH, ${ }^{3}$ \\ Owen T. Hill, PhD, ${ }^{3,4}$ Scott J. Montain, PhD, ${ }^{1}$ Andrew J. Young, PhD, ${ }^{1}$ Tracey J. Smith, PhD, $\mathrm{RD}^{1}$
}

Introduction: Little data exist regarding the long-term impact of excess weight on lower extremity musculoskeletal injury/disorder (MID) in U.S. Army Soldiers. This prospective analysis examines the association between BMI of Soldiers at accession and risk of MID.

Methods: A total of 736,608 Soldiers were followed from accession into the Army, 2001-2011. Data were analyzed January through March 2015. MID was categorized as any first incident lower extremity musculoskeletal injury/disorder, and secondarily, as first incident injury/disorder at a specific site (i.e., hips, upper legs/thighs, knees, lower legs/ankles, feet/toes). Multivariable-adjusted proportional hazards models estimated associations between BMI category at accession and MID risk.

Results: During 15,678,743 person-months of follow-up, 411,413 cases of any first MID were documented (70,578 hip, 77,050 upper leg, 162,041 knee, 338,080 lower leg, and 100,935 foot injuries in secondary analyses). The overall MID rate was 2.62 per 100 person-months. Relative to Soldiers with normal BMI $(18.5$ to $<25)$ at accession, those who were underweight $(<18.5)$; overweight $(25$ to $<30)$; or obese $(\geq 30)$ had $7 \%, 11 \%$, and $33 \%$ higher risk of MID, respectively, after adjustment. Risks were highest in Soldiers who were obese at accession, and lowest in those with a BMI of 21-23.

Conclusions: Soldier BMI at accession has important implications for MID. A BMI of 21-23 in newly accessing Soldiers was associated with the lowest risk of incident MID, suggesting that accession be limited to people within this range to reduce overall incidence of MID among service personnel.

(Am J Prev Med 2016;:(I):InI-nII) @ 2016 Published by Elsevier Inc. on behalf of American Journal of Preventive Medicine

\section{Introduction}

$\mathrm{O}$ veruse musculoskeletal injury and connective tissue disorder (MID) are common in activeduty military given the high volume of required physical activity. ${ }^{1-4}$ For example, in a recent study examining 1,633 men in 14-week combat engineering training, $47 \%$ experienced one or more such injuries. ${ }^{5}$ In another study investigating injuries across 18 weeks of

From the ${ }^{1}$ Military Nutrition Division, U.S. Army Research Institute of Environmental Medicine, Natick, Massachusetts; ${ }^{2}$ Department of Nutrition, Harvard T.H. Chan School of Public Health, Boston, Massachusetts; ${ }^{3}$ Environmental Medicine Military Performance Division, U.S. Army Research Institute of Environmental Medicine, Natick, Massachusetts; and ${ }^{4}$ Center for the Intrepid, Fort Sam, Houston, Texas

Address correspondence to: Tracey J. Smith, PhD, RD, Military Nutrition Division, U.S. Army Research Institute of Environmental Medicine, Kansas Street, Building 42, Natick MA 01760. E-mail: tracey. smith10.civ@mail.mil.

0749-3797/\$36.00

http://dx.doi.org/10.1016/j.amepre.2015.10.015 military police training, $34.2 \%$ of men and $66.7 \%$ of women experienced an injury. ${ }^{6}$ These reports confirm older studies $^{7-9}$ with similarly high rates of injury observed across longer study periods.

Overweight and obesity increase risk for MID. ${ }^{9,10}$ Excess body weight may be associated with injury for a number of reasons, such as added stress on the musculoskeletal system, greater muscle power requirements to compensate for difficulty performing aerobic tasks. ${ }^{11}$ An increasing trend in the prevalence of overweight and obesity in Soldiers newly accessing into the U.S. Army in 1989-2012 parallels the increasing prevalence in U.S. civilians. ${ }^{12}$ In the 1990s, musculoskeletal- and connective tissue-related hospitalizations and outpatient visits were lowest among Soldiers with a BMI of 19-22, but increased for Soldiers with higher BMI. ${ }^{9}$ Among 7,323 male Army trainees followed for 90 days (2005-2006), those who exceeded body fat standards at entry had $47 \%$ higher risk of any overuse injury, and a $49 \%$ higher 
number of injury-related outpatient visits versus weightqualified trainees. ${ }^{10}$ However, a study focusing on incident stress fractures during Basic Combat Training (BCT) in Army recruits ${ }^{13}$ found that the injury rate was higher among underweight Soldiers versus those with BMI $\geq 25$.

To date, most studies have examined Soldier risk factors for musculoskeletal injury in a relatively short time frame, have a relatively small sample size, or have not reported BMI. Therefore, the purpose here is to elucidate the long-term relationship between BMI and lower body MID in Soldiers first entering the Army between 2001 and 2011 (nearly the entire recruit population over a 10 -year period). The primary hypothesis is that overweight or obesity at accession is strongly associated with incident MID. These results may provide evidence for ongoing evaluation of Soldier weight-forheight criteria that would minimize the number of recruits at high MID risk owing to their BMI, with the ultimate goal of reducing the resource, economic, and health burden of MID in the U.S. Army.

\section{Methods}

\section{Study Design and Participants}

This study used existing historic data from the Total Army Injury and Health Outcomes Database (TAIHOD), 2001-2011. The TAIHOD is a data repository that maintains records of administrative and health-related data sets on active-duty Soldiers, and is used to support epidemiologic research. ${ }^{14}$ Data from the TAIHOD on enlisted personnel (excluding commissioned officers) were drawn from the following data sets: Military Entrance Processing Command data set, 2001-2011: date, height, and weight at application; Defense Manpower Data Center Master Personnel and Transaction data set, 2001-2011: date of birth, sex, race/ ethnicity, education, and marital status; and ICD-9 codes and dates corresponding to MID from inpatient/outpatient records from four clinical encounter data sets, 2002-2011 (Standard Inpatient Data Record; Standard Ambulatory Data Record; and TRICARE Encounter Data-Institutional and Non-Institutional). The interval between application and successful accession into the Army can be up to 18 months. ${ }^{15}$ There were 739,216 unique observations, 2001-2011, indicating individuals successfully accessed into the Army and were considered personnel thereafter. Excluded were $1,993(0.45 \%)$ participants missing or having implausible recorded height ( $<4.5$ or $\geq 7$ feet), weight $(<80$ or $\geq 450$ pounds) or calculated BMI $(<10$ or $\geq 50)$; $636(0.08 \%)$ missing information on date of birth; and two missing information on sexresulting in a sample total of 736,608 participants. This secondary data analysis was conducted January to March 2015 with approval from the IRB, U.S. Army Research Institute of Environmental Medicine, Natick, MA.

\section{Measures}

Soldiers' BMI $\left(\mathrm{kg} / \mathrm{m}^{2}\right)$ was calculated as weight $(\mathrm{kg})$ divided by height $(\mathrm{m})$, squared. Participants were categorized by baseline BMI as underweight $(<18.5)$, normal weight $(\geq 18.5$ to $<25)$, overweight $\left(\geq 25\right.$ to $<30$ ), or obese $(\geq 30) .{ }^{16}$ Screening Table Weights (STWs) from Army Regulation 40-501 (Standards of Medical Fitness) were used to categorize participants as under, meeting, or exceeding the weight-for-height criteria for accession in a given year. ${ }^{17}$ Persons entering the Army must meet age- and sex-specific weight-for-height screening criteria (Army Regulation 40-501), which are different from BMI thresholds ${ }^{16}$ and developed to align with a range of healthy BMI and body fat. ${ }^{18,19}$ When an individual exceeds maximum allowable weight-for-height criteria, body fat is the final determinant in evaluating an applicant's acceptability. ${ }^{17}$ Screening criteria and body fat standards have changed over time, as described for 2001-2011 in Appendix Tables 1 and 2 (available online). In analyses, the criteria in use at the time of a Soldier's accession were applied to that Soldier. Neither body fat nor physical fitness data were available.

The primary outcome was any post-accession incident MID identified by ICD- 9 codes related to inflammation and pain, joint derangement, dislocation, stress fracture, sprain, strain, and rupture, not obviously resulting from acute trauma (i.e., not contusions or crushes). Secondary analyses focused on MID to specific lower extremity sites: hips, upper legs, knees, lower legs and ankles, and feet and toes. Specific ICD-9 codes are in Appendix Table 3 (available online). Participants were considered cases if MID occurred following the accession date and prior to the last day of the last month in which they appeared in personnel files (date of Army separation) or the study cut-off date, December 31, 2011. The event date recorded was that of first MID (or sitespecific first MID for secondary analyses).

Demographics from personnel files included age, sex, educational attainment, race/ethnicity, and marital status (Table 1 lists categories of variables). Individuals with missing data on variables other than age, sex, and anthropometry were classified as "Other/ Unknown." Additional covariates included the Soldier's primary military occupation, derived from the personnel record dated closest to the accession date, and deployments in the time period of interest. Analyses including time-varying deployment and occupation (at 6-month intervals) did not substantively alter the results.

\section{Statistical Analysis}

Unadjusted percentages and means (SDs) of participant characteristics at baseline (accession) are presented by BMI category. Each Soldier's person-time (in months) at risk was calculated from the date of accession to the date of MID (any MID; secondarily, sitespecific MID), date of separation from the Army, or study cut-off date (December 31, 2011), whichever occurred first. To estimate the risk of incident MID as a function of BMI category, crude incidence, and incidence rates of any first MID and secondarily each site-specific MID were calculated. Hazard ratios and 95\% CIs of any first MID and secondarily any first site-specific MID were estimated using Cox proportional hazards models. Normal BMI $(18.5$ to $<25)$ was the ref category. Two models were considered: Model 1, adjusted for age and sex; and Model 2, additionally adjusted for race/ethnicity, educational attainment, marital status, primary military occupation, and history of deployment in the follow-up period. Survival curves were inspected for deviation from proportional hazards assumptions. Potential effect modification by sex or occupation was assessed by reanalyzing the data 
Table 1. Characteristics of 736,608 U.S. Army Soldiers at Accession by BMI Category, 2001-2011

\begin{tabular}{|c|c|c|c|c|c|}
\hline \multirow[b]{2}{*}{ Characteristic } & \multicolumn{3}{|c|}{ BMI Category } & \multirow[b]{2}{*}{$\begin{array}{c}\text { Obese } \\
\left(\geq 30 \mathrm{~kg} / \mathrm{m}^{2}\right)\end{array}$} & \multirow[b]{2}{*}{ Total } \\
\hline & $\begin{array}{l}\text { Underweight } \\
\left(<18.5 \mathrm{~kg} / \mathrm{m}^{2}\right)\end{array}$ & $\begin{array}{c}\text { Normal Weight } \\
\left(18.5-<25 \mathrm{~kg} / \mathrm{m}^{2}\right)\end{array}$ & $\begin{array}{c}\text { Overweight } \\
\left(25-<30 \mathrm{~kg} / \mathrm{m}^{2}\right)\end{array}$ & & \\
\hline$N(\%)$ & $17,530(2.4)$ & 392,702 (53.3) & 252,437 (34.3) & 73,939 (10.0) & 736,608 \\
\hline Sex, \% female & 27.5 & 21.0 & 14.3 & 2.3 & 17.0 \\
\hline Age, years (M, SD) & 20.8 (3.4) & $21.2(3.7)$ & $22.3(4.3)$ & $22.4(4.1)$ & $21.7(4.0)$ \\
\hline \multicolumn{6}{|l|}{ Age group, \% } \\
\hline$<20$ years & 56.1 & 51.1 & 39.0 & 34.9 & 45.5 \\
\hline $20-<30$ years & 40.8 & 44.8 & 54.2 & 58.6 & 49.3 \\
\hline $30-<40$ years & 3.1 & 3.9 & 6.4 & 6.2 & 5.0 \\
\hline$\geq 40$ years & 0.06 & 0.2 & 0.3 & 0.3 & 0.2 \\
\hline BMI (M, SD) & $17.9(0.6)$ & $22.1(1.7)$ & $27.1(1.4)$ & $32.1(1.8)$ & $24.8(3.8)$ \\
\hline \multicolumn{6}{|l|}{ Meets weight standard, \% } \\
\hline Under & 41.64 & 0.44 & 0.00 & 0.00 & 1.22 \\
\hline Meets & 58.2 & 96.6 & 50.5 & 0.00 & 70.2 \\
\hline Over & 0.13 & 3.0 & 49.5 & 100.0 & 28.6 \\
\hline \multicolumn{6}{|l|}{ Meets height standard, \% } \\
\hline Under & 0.02 & 0.10 & 0.06 & 0.05 & 0.08 \\
\hline Meets & 99.9 & 99.9 & 99.9 & 99.9 & 99.9 \\
\hline Over & 0.11 & 0.00 & 0.00 & 0.01 & 0.01 \\
\hline \multicolumn{6}{|l|}{ Race/ethnicity, \% } \\
\hline White & 67.0 & 66.8 & 66.7 & 63.1 & 66.4 \\
\hline Black & 18.0 & 17.6 & 14.7 & 17.6 & 16.6 \\
\hline Hispanic & 9.5 & 10.3 & 13.1 & 14.0 & 11.6 \\
\hline Asian/Pacific Islander & 4.4 & 4.1 & 4.1 & 4.1 & 4.1 \\
\hline Indian/Alaskan & 0.8 & 1.0 & 1.1 & 1.0 & 1.0 \\
\hline Other/unknown & 0.3 & 0.3 & 0.2 & 0.2 & 0.2 \\
\hline \multicolumn{6}{|l|}{ Education, \% } \\
\hline$<$ High school & 3.6 & 3.6 & 4.0 & 3.6 & 3.8 \\
\hline High school & 63.6 & 63.9 & 62.8 & 64.6 & 63.6 \\
\hline Some college/college & 19.9 & 19.6 & 20.8 & 19.4 & 20.0 \\
\hline Advanced degree & 0.1 & 0.3 & 0.5 & 0.3 & 0.3 \\
\hline Other/unknown & 12.8 & 12.6 & 11.9 & 12.2 & 12.3 \\
\hline \multicolumn{6}{|l|}{ Marital status, $\%$} \\
\hline Never married & 84.7 & 84.0 & 77.7 & 76.0 & 81.0 \\
\hline Married & 14.2 & 14.5 & 20.2 & 22.1 & 17.2 \\
\hline Divorced/separated/widowed & 1.0 & 1.5 & 2.1 & 1.8 & 1.7 \\
\hline
\end{tabular}


Table 1. Characteristics of 736,608 U.S. Army Soldiers at Accession by BMI Category, 2001-2011 (continued)

\begin{tabular}{|c|c|c|c|c|c|}
\hline \multirow[b]{2}{*}{ Characteristic } & \multicolumn{3}{|c|}{ BMI Category } & \multirow[b]{2}{*}{$\begin{array}{c}\text { Obese } \\
\left(\geq 30 \mathrm{~kg} / \mathrm{m}^{2}\right)\end{array}$} & \multirow[b]{2}{*}{ Total } \\
\hline & $\begin{array}{c}\text { Underweight } \\
\left(<\mathbf{1 8 . 5} \mathrm{kg} / \mathrm{m}^{2}\right)\end{array}$ & $\begin{array}{c}\text { Normal Weight } \\
\left(18.5-<25 \mathrm{~kg} / \mathrm{m}^{2}\right)\end{array}$ & $\begin{array}{c}\text { Overweight } \\
\left(25-<30 \mathrm{~kg} / \mathrm{m}^{2}\right)\end{array}$ & & \\
\hline Other/unknown & 0.04 & 0.07 & 0.08 & 0.07 & 0.07 \\
\hline Deployed, \% & 51.4 & 54.3 & 54.4 & 55.4 & 54.4 \\
\hline \multicolumn{6}{|l|}{ Military occupation } \\
\hline Infantry/gun crews & 35.6 & 38.9 & 41.8 & 43.2 & 40.2 \\
\hline Electronic equipment repair & 5.3 & 4.7 & 4.5 & 4.8 & 4.6 \\
\hline Communications/intelligence & 8.7 & 8.2 & 7.9 & 8.5 & 8.1 \\
\hline Enlisted health care & 5.3 & 5.5 & 5.4 & 4.9 & 5.4 \\
\hline Technical/allied specialist & 2.6 & 2.5 & 2.4 & 2.3 & 2.4 \\
\hline Support/administrative & 11.0 & 8.4 & 6.5 & 4.6 & 7.4 \\
\hline $\begin{array}{l}\text { Electrical/mechanical } \\
\text { equipment repair }\end{array}$ & 10.5 & 9.3 & 8.8 & 9.3 & 9.1 \\
\hline Craftsworkers & 1.6 & 1.6 & 1.5 & 1.5 & 1.5 \\
\hline Service/supply & 11.2 & 10.3 & 10.0 & 11.1 & 10.3 \\
\hline Non-occupational enlisted & 8.3 & 10.7 & 11.0 & 9.8 & 10.7 \\
\hline Other officer/specialist & 0.03 & 0.09 & 0.2 & 0.05 & 0.11 \\
\hline
\end{tabular}

after stratifying by these categories and comparing them to the results of the total population.

Potential non-linear relationships between BMI (continuous) and MID risk were explored non-parametrically with restricted cubic splines, ${ }^{20}$ and to estimate the nadir of BMI in relation to risk of MID. Ten automatically selected knots were used in the fully adjusted model, and, a priori, the median BMI of the population was selected as the ref level.

In secondary analyses of site-specific MID, given that history of post-accession MID to a site other than the site-specific MID being considered as the outcome of interest could be a mediator along the causal path, mediation analyses ${ }^{21}$ were used to estimate the proportion of the BMI-site-specific MID relationship explained by the history of a prior MID not at the specific lower extremity site of interest.

The regressions described above were repeated using STW categories in place of BMI categories, using "meeting STW" as the ref category. Statistics were performed using SAS, version 9.3. A two-sided $\alpha<0.05$ was considered statistically significant; however, $p$-values for almost every statistical test were $<0.001$ owing to the very large sample size. Therefore, point estimates and CIs are preferred to $p$-values as indicators of strength and consistency of associations.

\section{Results}

$34.3 \%$, and $10.0 \%$ who were underweight, overweight, and obese, respectively (Table 1 ). A greater proportion of men than women were overweight (35.4\% vs $28.8 \%$ ) and obese ( $11.8 \%$ vs $1.3 \%)$. Overweight and obesity prevalence was highest among Soldiers who self-identified as Hispanic compared with whites or blacks.

During 15,678,743 person-months of follow-up, there were 411,413 cases of any first MID; 55.9\% of Soldiers experienced at least one such event. Of those who experienced one or more first site-specific MID, there were 70,578 hip, 77,050 upper leg, 162,041 knee, 338,080 lower leg and ankle, and 100,935 foot MIDs. Overall diagnoses and site-specific diagnoses fluctuated nominally from 2001 to 2011; for example, knee MID accounted for $19.2 \%-23.2 \%$ of MID in any given year (data not shown). No time trends or cohort effects were evident.

The crude incidence rate of any (first) MID was 2.6 per 100 person-months (Table 2). Lower leg/ankle MID, the most common MID site, had the highest crude incidence rate of site-specific MID (1.8 per person-month). Crude MID rates were lowest among normal-weight Soldiers, whereas those classified as obese had the highest crude rates for all MID, except for the upper leg, wherein the rate was highest among underweight. After multivariate 
Table 2. Hazard Ratios (95\% Cls) of Lower Extremity Musculoskeletal Injury/Disorders across BMI Categories at Accession Among 736,608 Army Soldiers, 2001-2011

\begin{tabular}{|c|c|c|c|c|c|}
\hline \multirow[b]{3}{*}{ Injury/disorder } & \multicolumn{4}{|c|}{ Hazard ratio $(95 \% \mathrm{Cl})$} & \multirow[b]{3}{*}{ Total } \\
\hline & \multicolumn{4}{|c|}{ BMI category } & \\
\hline & $\begin{array}{c}\text { Underweight } \\
\left(<\mathbf{1 8 . 5} \mathbf{k g} / \mathbf{m}^{2}\right)\end{array}$ & $\begin{array}{c}\text { Normal weight } \\
\left(18.5-<25 \mathrm{~kg} / \mathbf{m}^{2}\right)\end{array}$ & $\begin{array}{c}\text { Overweight } \\
\left(25-<30 \mathrm{~kg} / \mathrm{m}^{2}\right)\end{array}$ & $\begin{array}{c}\text { Obese } \\
\left(\geq 30 \mathrm{~kg} / \mathrm{m}^{2}\right)\end{array}$ & \\
\hline \multicolumn{6}{|l|}{ Any $^{a}$} \\
\hline Cases, $n$ & 9,802 & 213,288 & 143,553 & 44,770 & 411,413 \\
\hline Time at risk ${ }^{\mathrm{b}}$ & 357,034 & $8,685,253$ & $5,234,792$ & $1,401,663$ & $15,678,743$ \\
\hline Incidence rate ${ }^{c}$ & 2.75 & 2.46 & 2.74 & 3.16 & 2.62 \\
\hline Model $1^{d}$ & $1.07(1.05,1.09)$ & 1 (ref) & $1.12(1.11,1.12)$ & $1.34(1.33,1.36)$ & \\
\hline Model 2 & $1.07(1.05,1.09)$ & 1 (ref) & $1.11(1.11,1.12)$ & $1.33(1.32,1.35)$ & \\
\hline \multicolumn{6}{|l|}{ Hip } \\
\hline Cases, $n$ & 1,511 & 35,755 & 25,313 & 7,999 & 70,578 \\
\hline Time at risk ${ }^{\mathrm{b}}$ & 648,950 & $15,107,575$ & $9,395,932$ & $2,618,746$ & $27,771,204$ \\
\hline Incidence rate ${ }^{c}$ & 0.23 & 0.24 & 0.27 & 0.31 & 0.25 \\
\hline Model $1^{\mathrm{d}}$ & $0.93(0.88,0.98)$ & 1 (ref) & $1.18(1.16,1.20)$ & $1.49(1.46,1.53)$ & \\
\hline Model 2 & $0.94(0.89,0.99)$ & 1 (ref) & $1.17(1.15,1.19)$ & $1.49(1.45,1.53)$ & \\
\hline \multicolumn{6}{|l|}{ Knee } \\
\hline Cases, $n$ & 3,654 & 82,518 & 57,312 & 18,557 & 162,041 \\
\hline Time at risk ${ }^{\mathrm{b}}$ & 567,776 & $13,281,013$ & $8,201,959$ & $2,264,049$ & $24,314,797$ \\
\hline Incidence rate ${ }^{\mathrm{C}}$ & 0.64 & 0.62 & 0.70 & 0.82 & 0.67 \\
\hline Model $1^{d}$ & $1.00(0.97,1.04)$ & 1 (ref) & $1.13(1.12,1.14)$ & $1.37(1.35,1.39)$ & \\
\hline Model 2 & $1.00(0.97,1.03)$ & 1 (ref) & $1.13(1.12,1.14)$ & $1.36(1.34,1.38)$ & \\
\hline \multicolumn{6}{|l|}{ Upper leg } \\
\hline Cases, $n$ & 2,132 & 42,399 & 25,622 & 6,897 & 77,050 \\
\hline Time at risk ${ }^{b}$ & 631,514 & $14,889,094$ & $9,363,080$ & 2635512.35 & $27,519,200$ \\
\hline Incidence rate ${ }^{C}$ & 0.34 & 0.28 & 0.27 & 0.26 & 0.28 \\
\hline Model $1^{d}$ & $1.06(1.02,1.11)$ & 1 (ref) & $1.06(1.04,1.07)$ & $1.27(1.24,1.31)$ & \\
\hline Model 2 & $1.06(1.01,1.11)$ & 1 (ref) & $1.06(1.04,1.07)$ & $1.28(1.25,1.32)$ & \\
\hline \multicolumn{6}{|l|}{ Lower leg/ankle } \\
\hline Cases, $n$ & 7,961 & 173,776 & 118,736 & 37,607 & 338,080 \\
\hline Time at risk $^{\mathrm{b}}$ & 426,571 & $10,208,794$ & $6,167,388$ & $1,658,274$ & $18,461,028$ \\
\hline Incidence rate ${ }^{C}$ & 1.87 & 1.70 & 1.93 & 2.27 & 1.83 \\
\hline Model $1^{\mathrm{d}}$ & $1.06(1.03,1.08)$ & 1 (ref) & $1.13(1.12,1.14)$ & $1.36(1.35,1.38)$ & \\
\hline Model 2 & $1.06(1.03,1.08)$ & 1 (ref) & $1.12(1.11,1.13)$ & $1.36(1.34,1.37)$ & \\
\hline \multicolumn{6}{|l|}{ Foot/toe } \\
\hline Cases, $n$ & 2,276 & 50,865 & 36,188 & 11,606 & 100,935 \\
\hline Time at risk ${ }^{\mathrm{b}}$ & 613,799 & $14,412,275$ & $8,913,380$ & $2,476,036$ & $26,415,491$ \\
\hline
\end{tabular}

444 
Table 2. Hazard Ratios (95\% Cls) of Lower Extremity Musculoskeletal Injury/Disorders across BMI Categories at Accession Among 736,608 Army Soldiers, 2001-2011 (continued)

\begin{tabular}{|c|c|c|c|c|c|}
\hline \multirow[b]{3}{*}{ Injury/disorder } & \multicolumn{4}{|c|}{ Hazard ratio $(95 \% \mathrm{Cl})$} & \multirow[b]{3}{*}{ Total } \\
\hline & \multicolumn{4}{|c|}{ BMI category } & \\
\hline & $\begin{array}{c}\text { Underweight } \\
\left(<18.5 \mathrm{~kg} / \mathrm{m}^{2}\right)\end{array}$ & $\begin{array}{c}\text { Normal weight } \\
\left(18.5-<25 \mathrm{~kg} / \mathrm{m}^{2}\right)\end{array}$ & $\begin{array}{c}\text { Overweight } \\
\left(25-<30 \mathrm{~kg} / \mathrm{m}^{2}\right)\end{array}$ & $\begin{array}{c}\text { Obese } \\
\left(\geq 30 \mathrm{~kg} / \mathrm{m}^{2}\right)\end{array}$ & \\
\hline Incidence rate ${ }^{c}$ & 0.37 & 0.35 & 0.41 & 0.47 & 0.38 \\
\hline Model $1^{d}$ & $1.01(0.97,1.06)$ & 1 (ref) & $1.15(1.13,1.17)$ & $1.40(1.37,1.43)$ & \\
\hline Model 2 & $1.01(0.97,1.06)$ & 1 (ref) & $1.15(1.13,1.16)$ & $1.40(1.37,1.43)$ & \\
\hline
\end{tabular}

a"Any" injury is defined as the first incident injury to any lower body site. Site-specific injury counts include only the first incident injury to the specific lower-body site.

${ }^{\mathrm{b}}$ Time at risk is given in person-months.

${ }^{\mathrm{C}}$ The incidence rate is given per 100 person-months.

${ }^{\mathrm{d}}$ Model adjustments are as follows: Model 1 was adjusted for age at baseline $(<20,20-<30,30-<40,40+$ years $)$ and sex. Model 2 was adjusted as for Model 1, plus the following sociodemographic covariates: race/ethnicity (white, black, Hispanic, Asian/Pacific Islander, Indian/Alaskan, other/ unknown); educational attainment (< high school, some college/college, advanced degree, other/unknown); marital status (never married, married, divorced/separated/widowed, other/unknown); primary military occupation; and deployment history.

adjustment, risk for any first MID was 33\%, 11\%, and 7\% higher among obese, overweight, and underweight Soldiers, respectively, versus normal-weight Soldiers (Table 2). Multivariate-adjusted MID risk to specific lower extremity sites was consistently higher among obese Soldiers than for those in lower BMI categories. CIs of risk estimates overlapped between underweight and normal-weight categories for knee MID and foot MID, indicating similar risk for these MID in these two BMI categories. However, underweight Soldiers had slightly lower risk for hip MID, and slightly higher risk for upper leg and lower leg MID, than normal-weight Soldiers. There was no substantive effect modification of MID risk by either sex or occupation.

Exploration of the non-linearity of these associations identified an accession BMI at the nadir of risk for any MID to be 21-23 (Figure 1; site-specific injuries, Appendix Figures 1-5, available online).

Prior lower extremity MID was evaluated as a potential mediator of the BMI-MID relationship. In analyses of incident hip MID, the relationship between BMI and post-accession non-hip MID (i.e., prior MID to other lower body extremities) accounted for $66.6 \%$ (95\% $\mathrm{CI}=62.4 \%, 70.8 \%)$ of the relationship between BMI and incident hip MID. For the remaining site-specific incident MID except lower leg injury, the mediating effects of prior MID were also high: upper leg, 50.5\% (41.9\%, $59.0 \%)$; knee, $52.4 \%$ (49.4\%, 55.4\%); foot, $62.5 \%$ (58.6\%, $66.5 \%)$. The proportion of the BMI-lower leg MID association explained by the BMI-prior MID association was $12.5 \%$ (11.4\%, 13.5\%), because lower leg/ankle MID was often the first event to occur.

Hazard ratios by STW categories mimicked those for BMI categories, with individuals under or over STW generally at higher risk of MID than those meeting STW (Appendix Table 4, available online).

\section{Discussion}

These results indicate higher risk of any incident lower extremity MID, and most site-specific MIDs, in Soldiers who were overweight or obese at Army entry compared with normal weight. There was also slightly elevated risk for MID among Soldiers who were underweight at entry, specifically for upper leg MID. The estimated ideal BMI for minimizing risk of MID was 21-23 for any initial event. Analyses that explored the role of BMI-prior MID relationship in BMI-incident site-specific MID indicated a considerable, if unsurprising, effect of prior MID on future MID at other sites. These analyses, coupled with the primary BMI-MID analyses and overall incidence rates, indicate a strong need for primary prevention measures.

Building on a long history of injury studies in Soldiers, these analyses evaluate injury risk over a longer duration, across a decade encompassing a period of increasing obesity prevalence in the applicant pool. Thus, it has implications for military recruiting, health, and healthcare costs. Prior studies had a relatively short follow-up (i.e., initial training period or 6-12-months), with a relatively small sample size, compared with the present analyses. Nevertheless, the present results align with some prior findings. In 2006, more than 740,000 musculoskeletal injuries were recorded among active-duty, non-deployed U.S. service members, for an injury rate of 628 per 1,000 person-years. ${ }^{1}$ Among these, $39 \%$ (approximately 245 per 1,000 person-years) were lower extremity overuse injuries, with knee/lower leg and ankle/foot 


\section{BMI and Incident Injury}

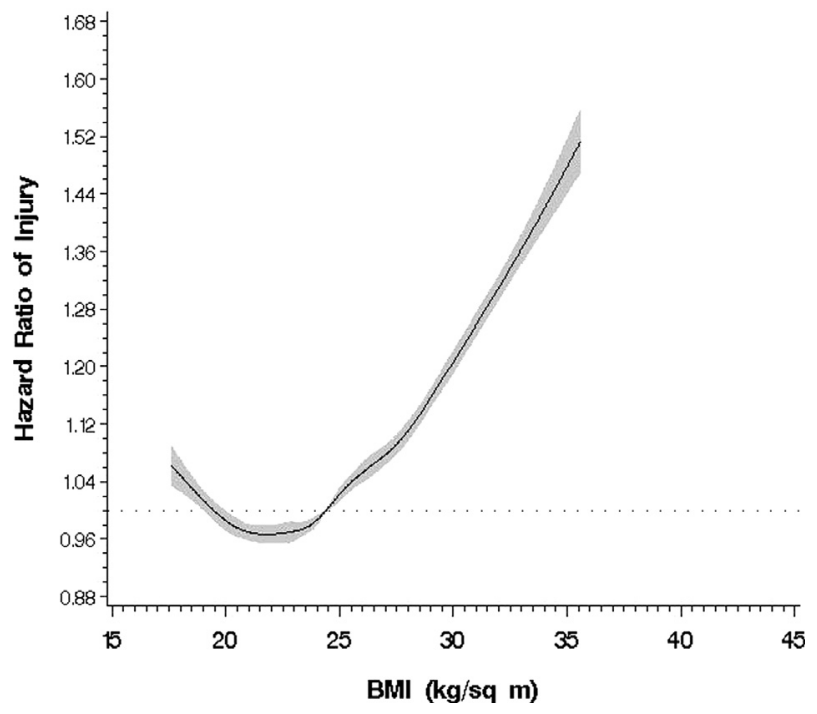

Figure 1. BMI at accession and risk of any incident lower extremity musculoskeletal injury/disorder in U.S. Army Soldiers, 2001-2011.

Proportional hazards models were adjusted for age at baseline, sex, race/ethnicity, educational attainment, marital status, primary military occupation, and deployment history. The risk estimates are given by the solid curve; $95 \% \mathrm{Cl}$ around the estimates are given by the shaded regions above and below the curve. The a priori reference value was the median BMI of the population, 24.4.

injuries representing 57\% and 33\%, respectively. ${ }^{1}$ The overall lower extremity MID rate observed presentlyaverage of 2.6 per 100 person-months (approximately 310 per 1,000 person-years) - is slightly higher than the 2006 rate; rate differences may be due to the present focus on the Army across a decade, whereas the 2006 analysis involved four military branches. ${ }^{1}$ Present results align with Cowan et al., ${ }^{10}$ who reported that trainees classified as exceeding body fat standards had higher crude injury rates than their weight-qualified peers, and $47 \%$ higher risk of an overuse injury, similar to the present results of 33\% higher risk for obese than normalweight Soldiers, also paralleled in the STW analyses.

The present results contrast with three short-term studies: a study of 584,000 Army recruits undergoing BCT reported higher odds for stress fracture among underweight recruits versus those in higher BMI categories $^{13}$; a 2013 study of recruits undergoing 19-week military police training, in which self-reported overweight or obesity was not associated with injury risk ${ }^{6}$; and a 2001 study during 8-week BCT, where there was no significant association between BMI or body fat and risk of back or lower extremity injury. ${ }^{22}$ Contrasting findings may be due to differences in study outcome measures, duration, or timing of BMI self-report or assessment. Notwithstanding these studies, the present results are supported by earlier findings covering longer periods. ${ }^{23-25}$ A 12-month study observed that approximately $80 \%$ of injuries in Infantry, Artillery, and Construction Engineers Soldiers were non-traumatic, and being overweight more than doubled injury risk. ${ }^{25}$ In Finnish conscripts serving 6-12 months, in 1998-2002, being overweight or obese increased the risk of lower-limb injury by $20 \%$ and $70 \%$, respectively. ${ }^{23}$ Longer service duration was noted by the authors to be a risk factor for injury. ${ }^{23}$ Thus, the longer follow-up in the Finnish and other studies, ${ }^{24}$ as in the present analysis, may underlie why some of the shorterterm studies did not observe associations between BMI and MID risk.

The identification of an ideal range of accession BMI for minimizing MID risk complements a retrospective cross-sectional study using earlier data (1990-1999) on related hospitalizations and outpatient visits in activeduty military, wherein self-reported BMI of 19-22 generally corresponded with the lowest injury-related outcomes within a 1-year time frame. ${ }^{9}$ In the present analysis, the multivariable-adjusted nadir of any MID was at an accession BMI of 21-23, a slight difference potentially owing to self-report and timing of self-report in the earlier study.

The importance of prior MID on future site-specific MID has been shown in earlier studies focusing on knee injuries using similar data. Hill and colleagues ${ }^{24,26}$ examined 2002-2005 rates of knee injury in active-duty Army, observing that Soldiers with a history of prior upper leg, lower leg, hip, or ankle injuries were at higher risk of incident knee injury. Schneider et al. ${ }^{27}$ also found that risk of injury increased substantively with history of prior injury among Army Airborne Soldiers. Present results support these trends over the longer term across active-duty Soldiers with the added explanatory factor of BMI as a key risk factor for prior and future MID.

There are several novel aspects and strengths of this study. Data were derived from an exceptionally large database including inpatient and outpatient medical records, across a recent, decade-long period that coincided with an increasing prevalence of civilian adolescent and young adult overweight and obesity. ${ }^{28-30}$ These Soldiers comprise nearly the entire recruit population in this time frame. Thus, findings are relevant to recruiting increasingly rare low-risk applicants from the civilian applicant pool owing to the ongoing challenges of the obesity epidemic. The present analysis examined the specific association of recruits' recorded BMI at application to the Army and the risk of MID as these Soldiers underwent intensive initial training, followed throughout their active-duty careers. Further, this analysis identified a BMI range in newly accessing Soldiers with the lowest risk for potentially preventable MID, suggesting a target 
BMI range for recruitment that would minimize MID burden.

\section{Limitations}

This study has several limitations. Data on fitness or body fat, which have been shown to mediate relationships between BMI and morbidity ${ }^{10,31}$ and could have added to understanding weight-related MID risk, were not available. Additionally, only BMI measures for Soldiers at the time of acceptance into the Army were available, but weight has been shown to improve (increase if underweight, decrease if overweight) prior to BCT (up to 18 months) and throughout BCT. ${ }^{32}$ From these data, there is no reliable way to assess lag time between accession and BCT, and BMI could have changed in that period. Future work could focus on potential effects of changes in BMI occurring prior to and during BCT on MID risk. Although the TAIHOD includes data on both deployed and non-deployed Soldiers, deployment injuries are likely under-represented. Finally, it is impossible to distinguish from ICD-9 codes alone whether an injury was acute or chronic, and this information may have resulted in a more nuanced understanding of BMI's role in MID.

\section{Conclusions}

These findings indicate that BMI (and STW) status at accession is strongly associated with lower extremity MID in active-duty Soldiers. Newly accessing Soldiers with a BMI of 21-23 had the lowest risk for potentially preventable MID, suggesting a target BMI range for recruitment that would minimize MID burden. Continuing enhancement of existing initiatives to prevent MID are also warranted.

The authors would like to thank the millions of U.S. Army Soldiers who, in entering into military service for this country, contributed their data to this analysis. The opinions or assertions contained herein are the private views of the authors and are not to be construed as official or reflecting the views of the Army or the Department of Defense. Any citations of commercial organizations and trade names in this report do not constitute an official Department of the Army endorsement of approval of the products or services of these organizations. AH's contribution to this research was supported by an appointment to the Postgraduate Research Participation Program at the U.S. Army Medical Research Institute of Environmental Medicine administered by the Oak Ridge Institute for Science and Education through an interagency agreement between the U.S. Department of Energy and U.S. Army Medical Research and Materiel Command.
Author contributions are as follows. TJS conceived of and designed the study. CJM, OTH, and LB contributed to the study design, data acquisition, and interpretation. AH conducted the analyses and drafted the manuscript. TJS, SJM, and AJY revised the article for important intellectual content. All authors read and approved the final version of the manuscript.

No financial disclosures were reported by the authors of this paper.

\section{References}

1. Hauret KG, Jones BH, Bullock SH, Canham-Chervak M, Canada S Musculoskeletal injuries: description of an under-recognized injury problem among military personnel. Public Health Approach Inj Prev US Mil Exp. 2010;38(1 suppl):S61-S70. http://dx.doi.org/10.1016/j. amepre.2009.10.021.

2. Knapik JJ, Hauret KG, Jones BH. Chapter 8. Primary prevention of injuries in initial entry training. In: Lenhart MK, Lounsbury DE, North RB Jr., eds. Textbooks of Military Medicine: Recruit Medicine. Washington, DC: Office of the Surgeon General, 2006:125-146 https://ke.army.mil/bordeninstitute/published_volumes/recruit_medicine/ RM-ch08.pdf.

3. Zambraski EJ, Yancosek KE. Prevention and rehabilitation of musculoskeletal injuries during military operations and training. J Strength Cond Res. 2012;26(suppl 2):S101-S106. http://dx.doi.org/10.1097/ JSC.0b013e31825cf03b.

4. Nindl BC, Williams TJ, Deuster PA, Butler NL, Jones BH. Strategies for optimizing military physical readiness and preventing musculoskeletal injuries in the 21st century. US Army Med Dep J. 2013:5-23.

5. Knapik JJ, Graham B, Cobbs J, Thompson D, Steelman R, Jones BH. A prospective investigation of injury incidence and risk factors among army recruits in combat engineer training. J Occup Med Toxicol. 2013;8 (1):5. http://dx.doi.org/10.1186/1745-6673-8-5.

6. Knapik JJ, Graham B, Cobbs J, Thompson D, Steelman R, Jones BH. A prospective investigation of injury incidence and injury risk factors among Army recruits in military police training. BMC Musculoskelet Disord. 2013;14:32. http://dx.doi.org/10.1186/1471-2474-14-32.

7. Tiesman HM, Peek-Asa CL, Zwerling CS, Sprince NL, Amoroso PJ. Occupational and non-occupational injuries in the United States Army: focus on gender. Am J Prev Med. 2007;33(6):464-4701. http: //dx.doi.org/10.1016/j.amepre.2007.07.034.

8. Knapik J, Ang P, Reynolds K, Jones B. Physical fitness, age, and injury incidence in infantry soldiers. J Occup Med. 1993;35(6):598-603. http: //dx.doi.org/10.1097/00043764-199306000-00017.

9. Washington S. Relationship between body mass index and musculoskeletal system and connective tissue disorders, US Army, 19901999. Med Surveill Mon Rep. 2000;6(7): www.afhsc.mil/documents/ pubs/msmrs/2000/v06_n07.pdf.

10. Cowan DN, Bedno SA, Urban N, Yi B, Niebuhr DW. Musculoskeletal injuries among overweight army trainees: incidence and health care utilization. Occup Med (Lond). 2011;61(4):247-252. http://dx.doi.org/ 10.1093/occmed/kqr028.

11. Wearing SC, Hennig EM, Byrne NM, Steele JR, Hills AP. Musculoskeletal disorders associated with obesity: a biomechanical perspective. Obes Rev. 2006;7(3):239-250. http://dx.doi.org/10.1111/j.1467-789X.2006.00251.x.

12. Hruby A, Hill OT, Bulathsinhala L, et al. Trends in overweight and obesity in soldiers entering the U.S. Army, 1989-2012. Obesity. 2015;23 (3):662-670. http://dx.doi.org/10.1002/oby.20978.

13. Knapik J, Montain SJ, McGraw S, Grier T, Ely M, Jones BH. Stress fracture risk factors in basic combat training. Int J Sports Med. 2012;33 (11):940-946. http://dx.doi.org/10.1055/s-0032-1311583. 
14. Amoroso PJ, Yore MM, Weyandt B, Jones BH. Chapter 8. Total Army Injury and Health Outcomes Database: a model comprehensive research database. Mil Med. 1999;164(8 suppl):1-36.

15. DeKoning B, ed. Recruit Medicine. Washington, DC: Borden Institute, Walter Reed Army Medical Center; Fort Sam Houston, TX: U.S. Army Medical Dept. Center and School; Falls Church, VA: Office of the Surgeon General, U.S. Army; 2006.

16. NIH, National Heart, Lung, and Blood Institute. Obesity Education Initiative: Clinical Guidelines on the Identification, Evaluation, and Treatment of Overweight and Obesity in Adults: Executive Summary. Expert Panel on the Identification, Evaluation, and Treatment of Overweight in Adults. Bethesda, MD: USDHHS; 1998. www.ncbi. nlm.nih.gov/books/NBK2003/. Accessed April 1, 2014.

17. U.S. Department of the Army. Standards of Medical Fitness, Army Regulation 40-501. http://armypubs.army.mil/epubs/40_Series_Collec tion_1.html. Accessed April 1, 2014.

18. Friedl KE. Can you be large and not obese? The distinction between body weight, body fat, and abdominal fat in occupational standards. Diabetes Technol Ther. 2004;6(5):732-749. http://dx.doi.org/10.1089/ dia.2004.6.732.

19. Friedl KE. Body composition and military performance-many things to many people. J Strength Cond Res Natl Strength Cond Assoc. 2012;26 (suppl 2):S87-S100. http://dx.doi.org/10.1519/JSC.0b013e31825ced6c.

20. Li R, Hertzmark E, Louie M, Chen L, Spiegelman D. The SAS LGTPHCURV9 Macro. www.hsph.harvard.edu/donna-spiegelman/ software/lgtphcurv9/. Published July 2011. Accessed February 12, 2015.

21. Hertzmark E, Pazaris M, Spiegelman D. The SAS MEDIATE Macro. www.hsph.harvard.edu/donna-spiegelman/software/mediate/. Published June 2012. Accessed February 12, 2015.

22. Knapik JJ, Sharp MA, Canham-Chervak M, Hauret K, Patton JF, Jones $\mathrm{BH}$. Risk factors for training-related injuries among men and women in basic combat training. Med Sci Sports Exerc. 2001;33(6):946-954. http://dx.doi.org/10.1097/00005768-200106000-00014.

23. Mattila VM, Kuronen P, Pihlajamäki $H$. Nature and risk factors of injury hospitalization in young adults: a follow-up of 135,987 military conscripts. Scand J Public Health. 2007;35(4):418-423. http://dx.doi. org/10.1080/14034940601181439.

24. Hill OT, Bulathsinhala L, Scofield DE, Haley TF, Bernasek TL. Risk factors for soft tissue knee injuries in active duty U.S. Army soldiers,
2000-2005. Mil Med. 2013;178(6):676-682. http://dx.doi.org/10.7205/ MILMED-D-13-00049.

25. Reynolds K, Cosio-Lima L, Bovill M, Tharion W, Williams J, Hodges T. A comparison of injuries, limited-duty days, and injury risk factors in infantry, artillery, construction engineers, and special forces soldiers. Mil Med. 2009;174(7):702-708. http://dx.doi.org/10.7205/MILMED-D-02-2008.

26. Hill OT, Kay AB, Wahi MM, McKinnon CJ, Bulathsinhala L, Haley TF. Rates of knee injury in the U.S. Active Duty Army, 2000-2005. Mil Med. 2012;177(7):840-844. http://dx.doi.org/10.7205/MILMED-D-11-00313.

27. Schneider G. Evaluating risk of re-injury among 1214 Army Airborne soldiers using a stratified survival model. Am J Prev Med. 2000;18 (1):156-163. http://dx.doi.org/10.1016/S0749-3797(99)00177-4.

28. Fryar CD, Carroll MD, Ogden CL.NCHS Health E Stat-overweight, obesity, and extreme obesity among adults: United States, trends 19601962 through 2009-2010. www.cdc.gov/nchs/data/hestat/obesity_a dult_09_10/obesity_adult_09_10.htm. Accessed February 26, 2014.

29. Fryar CD, Carroll MD, Ogden CL. NCHS Health E Stat-prevalence of obesity among children and adolescents: United States, trends 1963-2965 through 2009-2010. www.cdc.gov/nchs/data/hestat/obesi ty_child_09_10/obesity_child_09_10.htmtable1. Accessed May 4, 2014.

30. Ogden CL, Carroll MD, Kit BK, Flegal KM. Prevalence of childhood and adult obesity in the United States, 2011-2012. JAMA. 2014;311 (8):806. http://dx.doi.org/10.1001/jama.2014.732.

31. Bedno SA, Cowan DN, Urban N, Niebuhr DW. Effect of pre-accession physical fitness on training injuries among U.S. Army recruits. Work Read Mass. 2013;44(4):509-515. http://dx.doi.org/10.3233/WOR-2012-1355.

32. Williamson DA, Martin PD, Allen HR, et al. Changes in food intake and body weight associated with basic combat training. Mil Med. 2002;167(3):248-253. 